\title{
A CLINICAL STUDY OF HEART DISEASE IN PREGNANCY AT GOVERNMENT MATERNITY HOSPITAL
}

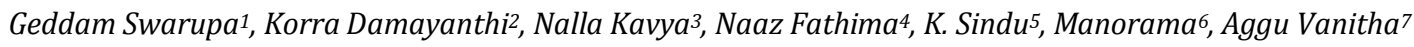

1 Post Graduate Student, Department of Obstetrics and Gynaecology, Osmania Medical College, Hyderabad, Telangana, India. ${ }^{2}$ Assistant Professor, Department of Obstetrics and Gynaecology, Osmania Medical College, Hyderabad, Telangana, India. 3 Post Graduate Student, Department of Obstetrics and Gynaecology, Osmania Medical College, Hyderabad, Telangana, India. ${ }_{4}^{4}$ Post Graduate Student, Department of Obstetrics and Gynaecology, Osmania Medical College, Hyderabad, Telangana, India. 5Post Graduate Student, Department of Obstetrics and Gynaecology, Osmania Medical College, Hyderabad, Telangana, India. ${ }_{6}^{6}$ Post Graduate Student, Department of Obstetrics and Gynaecology, Osmania Medical College, Hyderabad, Telangana, India. 7Post Graduate Student, Department of Obstetrics and Gynaecology, Osmania Medical College, Hyderabad, Telangana, India.

\section{BACKGROUND}

ABSTRACT

${ }^{1}$ Heart disease is the fourth most common cause of maternal death and the most common indirect cause of maternal mortality. The physiological adaptation of normal pregnancy can induce symptoms and alter clinical findings that may confound the diagnosis of heart disease. The obstetrician providing care for pregnant women with heart disease is now faced with different spectrum of heart diseases compared with her counterparts two to three decades earlier. ${ }^{2}$ Women with severe heart disease will benefit immensely from counselling before deciding to become pregnant. 3 There is decrease in the frequency of rheumatic fever and its related heart disease concomitant with the improvement in medical and surgical therapy. Due to industrialisation and changing cultural trends, incidence of ischemic heart disease is slowly increasing in women of reproductive age groups. We conducted a study to evaluate the influence of biological factors like age, gravidity, duration of pregnancy and mode of labour when pregnancy is complicated by heart disease and to study the changing trends in the types of heart disease, clinical presentation, investigations, management and outcomes in cases of heart disease complicating pregnancy. The onset of an attack of acute rheumatism superimposed upon a damaged heart during pregnancy is a serious condition.

Study Objectives-

1. To evaluate the influence of biological factors like age, gravidity, duration of pregnancy and mode of labour when pregnancy is complicated by heart disease.

2. To study the changing trends in the types of heart disease, clinical presentation, investigations, management and outcomes in cases of heart disease complicating pregnancy. 4

\section{MATERIALS AND METHODS}

In this Descriptive study, we studied 50 cases of heart disease complicating pregnancy and followed them from antenatal outpatient department. 2D echo with Doppler study was used as a confirmatory investigation. The cases were classified as proposed by revised New York Heart Association i.e. the aetiological diagnosis, anatomical diagnosis, physiological classification, cardiac status or functional classification and therapeutic classification or prognosis. Functional class 1 patients were advised to have regular antenatal check-ups while functional class $3 \& 4$ patients were admitted as soon as they reported. No diagnostic or therapeutic interventions were withheld for optimal maternal safety.

\section{RESULTS}

We studied 50 cases of heart disease complicating pregnancy during the study period. Incidence of cardiac disease was found to be $0.42 \%$ in the present study. Most of the study population were in the age group of $21-25$ years. About $90 \%$ of the cases in this study were belonging to low socio-economic status. Most of the patients were multi gravidas (66\%). $70 \%$ patients had chronic rheumatic heart disease. Mitral valve was involved in all cases except in a case of pure TR. As the age and gravidity increased the functional grade seemed to be increasing in this study. Single maternal death occurred in this study and belonged to class $4.24 \%$ of cases had anaemia with $\mathrm{Hb}$ less than $10 \mathrm{gm} / \mathrm{dl} .22 \%$ patients had pregnancy induced hypertension. Maximum number of cardiac failures were noted during intrapartum period and immediate postpartum period. $50 \%$ of patients had spontaneous vaginal delivery. $14 \%$ needed an assistance with outlet forceps. Caesarean section was done in $20 \%$ of patients purely for obstetrical reasons. Most common presentation is vertex. Birthweight over $2.5 \mathrm{~kg}$ is seen in about $58.5 \%$ cases. One still birth in this study was due to rupture uterus.

\section{CONCLUSION}

$50 \%$ patients with heart disease in pregnancy were reviewed for the period August 2017-2018. Incidence of heart disease is found to be $0.42 \%$. Incidence of rheumatic heart disease has decreased, and the incidence of congenital heart diseases has increased. Maximum number of cases was seen in 21-25 years age group. But it is found that there is a percentage increase of the cases in 1620 years age group, which can be attributed to increased incidence of congenital heart disease in this study. Age and gravidity were found to correlate with the functional class of heart disease. Most of the study cases were from a low socio-economic group and from urban slums. Most of them had vaginal deliveries and 20\% had LSCS for obstetrical indications. The incidence of LSCS is noted to be rising. Duration of labour both in primigravidas and multigravidas was found to be decreased when compared with the previous studies. There is a decreased incidence in the preterm babies and babies weighing less than 2 Kgs, compared to 1992 study at GMH. Perinatal mortality was $23.25 / 1000$ births. Pregnancy outcome greatly varies when the pregnant cardiac is booked case and when she is constantly looked after by a cardiologist \& obstetrician with a touch of personal care.

\section{KEY WORDS}

Heart Disease, Pregnancy, Mode of Labour. 
HOW TO CITE THIS ARTICLE: Swarupa G, Damayanthi K, Kavya N, et al. A clinical study of heart disease in pregnancy at government maternity hospital. J. Evolution Med. Dent. Sci. 2018;7(45):4919-4925, DOI: 10.14260/jemds/2018/1095

'Financial or Other Competing Interest': None.

Submission 25-09-2018, Peer Review 19-10-2018,

Acceptance 25-10-2018, Published 05-11-2018.

Corresponding Author:

Dr. Banoth Damayanthi,

Flat No. 4134, $4^{\text {th }}$ Block, $2^{\text {nd }}$ Wing,

$1^{\text {st }}$ Floor, Janapriya Metropolis,

Motinagar, Erragadda, Hyderabad-500018,

Telangana, India

E-mail: karradamayanthi@gmail.com

DOI: $10.14260 /$ jemds $/ 2018 / 1095$

\section{(c) $(1)(-)$}

\section{BACKGROUND}

Patterns of heart disease vary geographically and socioeconomically and have changed over time, especially during the last five decades. Heart disease occurs in approximately $1-2 \%$ of all pregnancies. $1 \%$ according to Lamy C Grilstyin et al 1989; Macnat G et al 1985 reported 0.3\%; Mandelson 1940 3.5\%.

${ }^{5}$ After hypertension, haemorrhage and infection, heart disease is the fourth most common cause of maternal death and the most common indirect cause of maternal mortality. The obstetrician providing care for pregnant women with heart disease is now faced with different spectrum of heart diseases compared with her counterparts two to three decades earlier. There is decrease in the frequency of rheumatic fever and its related heart disease concomitant with the improvement in medical and surgical therapy. Due to industrialisation and changing cultural trends, incidence of ischemic heart disease is slowly increasing in women of reproductive age groups. ${ }^{6}$ Pregnancy increase the risk of acute myocardial infarction by 3-4-fold, with risk being 30 times higher in women more than 40 years of age as compared to less than 20 yrs.

Cardiac diseases jeopardise the mother during pregnancy, labour \& puerperium and the foetus throughout. Fortunately, under good supervision, provided that the extra demands of pregnancy are satisfactorily met at the time, it should generally be possible for the patient to emerge from the experience of child birth without any degradation in her cardiac condition, and this should be the obstetrician aim. Any complication however is likely to increase cardiac strain, and in this subject too "prevention is better than cure". (Ian Donald).

In the last few years, progress concerning our understanding of heart disease in pregnancy has been dissipated in several areas of interest. As in so many other topics in medicine there has been a major breakthrough, and a series of related advances. Besides traditional specific noninvasive methods like chest x-ray, ECG, phonocardiogram, carotid pulse tracings the advent of echocardiogram has revolutionised cardio vascular medicine. Angiocardiography and cardiac catheterisation are examples of invasive technique (which (Catheterisation) (are) especially useful for early and accurate diagnosis of congenital heart disease. But usually invasive procedures are not recommended in pregnant woman.

Echo cardiogram is the choice of investigation in pregnant women with Heart disease. As it is important to determine the real nature of the condition so that appropriate management can be instituted. Greater safety of the pregnant patient with heart disease has been attained mainly through better appreciation of the physiologic changes occurring during pregnancy and improved knowledge of the natural history of the complicating cardiac disease together with more recent advances in medical and surgical therapy.

The clinical presentation of cases is changing. They range from less number of unbooked cases with class IV Symptoms to more number of well compensated booked cases, varieties of congenital heart diseases; Post valvotomy cases \& even Cardiac Bypass Surgery during pregnancy. In this study we have not encountered a case with valve replacement.

When there is a close co-ordination and co-operation among the Obstetrician, Cardiologist Cardiothoracic Surgeon, Anaesthetist, Neonatologist, the nursing staff and the family members of the patient, only then an optimal benefit can be achieved from the existing facilities that are available.

\section{MATERIALS AND METHODS}

The Descriptive study, 50 cases of heart disease complicating pregnancy have been studied at Govt. maternity Hospital Petlaburz.

The cases were followed up from the Antenatal outpatient. All the cases with suspicious heart disease were subjected to a thorough history\& clinical examination followed by ECG. 2D echo with Doppler study was used as a confirmatory investigation. Only the cases with confirmed Heart Disease were taken and the rest were eliminated from the study group.

After the identification of the heart disease, cases were classified, as proposed by revised New York Heart Association. i.e. the etiological diagnosis, anatomical diagnosis Physiological classification, cardiac status or functional classification and Therapeutic classification or prognosis. Maternal health is given the highest priority, but certainly measures to protect the fetus are also considered. No diagnostic or therapeutic (Available) intervention were withheld for optimal maternal safety.

Preconceptional counseling, especially for the patients with congenital heart disease is ideal. Unfortunately, none of the cases in the study had preconceptional counseling. However, the potential risks for the mother and fetus were discussed with the patients and the family members. In a case of severe primary pulmonary hypertension and in a case of peripartum cardiomyopathy with persistent cardiomegaly termination of pregnancy was advised in the interest of the Mother.7 It is always better to have a cardiologist anaesthetist \& a paediatrician who are well aware of the problem, to be made readily available when ever required.

Factors that serve to aggravate heart disease and needlessly encroach in cardiac reserve are identified \& removed or at least minimised. Anxiety is a source of stress. Reassurance begins with a frank, clear explanation designed to remove fear of the unknown. The expectant mother is told what to anticipate during each stage of pregnancy. Restriction of Physical activity and Physical rest which include 10-12 
hours rest in the night $\& 2$ hours rest in the early afternoon is advised.

8Patients are advised against gaining excessive weight, as increase in weight increases the risk of thrombophlebitis, infection in addition to the extra burden on heart. Inactive cardiac patients need fewer calories with optimal protein intake which is between $80-90 \mathrm{gm} /$ day. Restriction of sodium intake to $2 \mathrm{gm} /$ day is recommended to prevent excessive fluid retention. Oral Iron \& Folic acid supplementation is started as soon as the patients report at the hospital. Factors which aggravate the cardiac dysfunction, (Such as hyperthyroidism, infections, thromboembolism, arrhythmias, $\mathrm{PIH}$, anaemia) are looked for during the antenatal check-ups, so as to enable early detection and prompt treatment. Patients were mostly managed on outpatient basis unless this condition necessitated admission. Patients were advised to have a house help during pregnancy and in the puerperium.

\section{RESULTS}

Functional class I patients were advised to have regular antenatal check-ups. Rheumatic fever prophylaxis is given for CRHD cases. They were informed to report immediately if they found deterioration in their functional class or when they gain excess Weight rapidly. (Patients who came from far off rural areas were admitted in the hospital purely on the convenience basis) functional status was reassessed in every antenatal visit. Functional class III \&IV patients were admitted as soon as they reported.

\begin{tabular}{|c|c|}
\hline Total number of admissions during the period August 2017 to August 2018 are & 14300 \\
\hline Total number of pregnant cardiac disease & 60 \\
\hline Number of cases studied & 50 \\
\hline Percent of Pregnant cardiac patients during the period, at GMH & $0.42 \%$. \\
\hline 2015 GMH study the incidence was & $0.43 \%$ \\
\hline An increased incidence was noted in the months July to Oct 1993 & \\
\hline Table 1. Incidence of Cardiac Disease in This Study &
\end{tabular}

\begin{tabular}{|c|c|c|c|c|c|c|}
\hline & 16-20 Yrs. & 21-25 Yrs. & 26-30 Yrs. & 31-35 Yrs. & 35-40 Yrs. & Total \\
\hline Present Study & 16 & 18 & 12 & 3 & 1 & 50 \\
\hline 1992 GMH Study & 20 & 35 & 25 & 12 & 8 & 100 \\
\hline Leela Series 1968 & 16 & 20 & 32 & 22 & 8 & 100 \\
\hline Subhadra Devi 1950-56 & 28 & 26 & 34 & 12 & 5 & 105 \\
\hline \multicolumn{7}{|c|}{ Table 2. Age Distribution of Cases } \\
\hline
\end{tabular}

Maximum percentage of cases were found to be in the 2125 Year age group. But the percentage of cases in 16-20 Year age group have increased. Probably due to an increased incidence of congenital heart disease. When compared to
1992 study there is a decrease in percentage of cases in the age groups 31-35 year \& 35-40 year, probably due to effective family planning programme and also due to completion of child bearing at an early age.

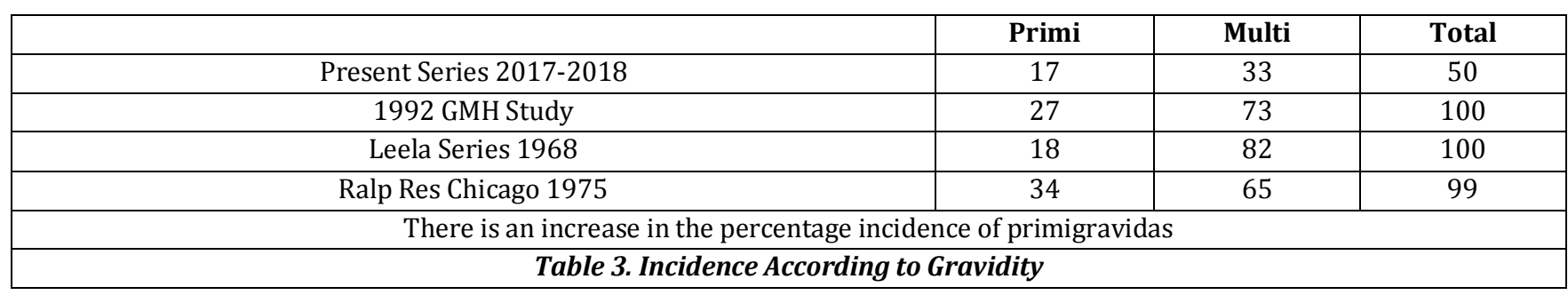

\begin{tabular}{|c|c|c|c|c|}
\hline & & & \multicolumn{2}{|c|}{ Percentage } \\
\hline Sl. No. & Present & $\mathbf{1 9 9 2}$ & Present & 1992 \\
\hline 1 & 17 & 27 & $34 \%$ & $27 \%$ \\
\hline 2 & 14 & 25 & $18 \%$ & 25 \\
\hline 3 & 9 & 19 & $2 \%$ & 9 \\
\hline 4 & 1 & 9 & $14 \%$ & 7 \\
\hline 5 & 7 & 7 & $4 \%$ & 10 \\
\hline 6 & 2 & 10 & - & 3 \\
\hline 7 & - & 3 & 50 & 100 \\
\hline
\end{tabular}

There is an increased incidence of primigravidas in the present study and a decrease in the incidence of all the gravidas except the fifth. There were no 7 th gravidas. 


\begin{tabular}{|c|c|}
\hline Rural & 14 \\
\hline Urban & 12 \\
\hline Urban Slum & 24 \\
\hline \multicolumn{2}{|c|}{ Majority of the cases with ARHD were belonging to urban slum } \\
\hline \multicolumn{2}{|c|}{ Table 5. Residence Distribution } \\
\hline
\end{tabular}

\begin{tabular}{|c|c|c|}
\hline Aetiology & No. of Cases & Percentage \\
\hline Rheumatic & 35 & $70 \%$ \\
\hline Congenital & 9 & $18 \%$ \\
\hline Primary Pulm.HTN & 1 & $2 \%$ \\
\hline Myocarditis & 1 & $2 \%$ \\
\hline Conduction Defects RBBB & 2 & $4 \%$ \\
\hline Cardio Myopathy Constrictive & 1 & $2 \%$ \\
\hline Dilated & 1 & $2 \%$ \\
\hline \multicolumn{3}{|c|}{ Table 6. Aetiology Distribution } \\
\hline
\end{tabular}

Dilated Cardiomyopathy in previous pregnancy, presently with persistent cardiomegaly, MTP sterilization was done for this case.

\begin{tabular}{|c|c|c|}
\hline & CRHD & $\begin{array}{c}\text { Congenital Heart } \\
\text { Disease }\end{array}$ \\
\hline Present Study & $70 \%$ & $18 \%$ \\
\hline GMH 1977 & $90 \%$ & $10 \%$ \\
\hline GMH 1975-80 & $86.54 \%$ & $11.54 \%$ \\
\hline Subhadra Devi 1956 & $88 \%$ & ---- \\
\hline \multicolumn{2}{|c|}{ Table 7. Aetiology Comparison } \\
\hline
\end{tabular}

There is an increased incidence of congenital heart disease and a decreased incidence of chronic rheumatic heart disease.

\begin{tabular}{|c|c|c|}
\hline Lesion & No. of Cases & Percentage \\
\hline MS & 8 & $22.85 \%$ \\
\hline MS PAH & 7 & $20 \%$ \\
\hline MS MR & 6 & $17.15 \%$ \\
\hline MS MR AR & 2 & $5.7 \%$ \\
\hline MS MR AR & 5 & $14.3 \%$ \\
\hline MS MR AS PAH & 1 & $2.85 \%$ \\
\hline MS MR TR PAH & 2 & $5.7 \%$ \\
\hline MS AR PAH & 1 & $2.85 \%$ \\
\hline MS TR PAH & 1 & $2.85 \%$ \\
\hline TR & 1 & $2.85 \%$ \\
\hline \multicolumn{3}{|c|}{ Table 8. Distribution of Valvular Lesions } \\
\hline
\end{tabular}

The findings show that the most commonly involved valve is the mitral valve corroborating earlier studies. All the cases except one case, mitral valve was found to be diseased. The exception being a case of pure TR. The next commonly effected valve was found to be the aortic valve and a regurgitant lesion is more commonly seen.

\begin{tabular}{|c|c|c|}
\hline Lesion & Present Study & 1992 Study \\
\hline MS & $42.85 \%$ & $64.5 \%$ \\
\hline MS MR & $22.85 \%$ & $20 \%$ \\
\hline MR & ---- & $6.7 \%$ \\
\hline MS AR & $2.85 \%$ & $3.3 \%$ \\
\hline Table 9. Percentage of Lesions Compared To 1977 Study \\
\hline
\end{tabular}

There is a slight increase in the incidence of MS MR compared to the previous study. This could be because the post CMV cases had MR after CMV.

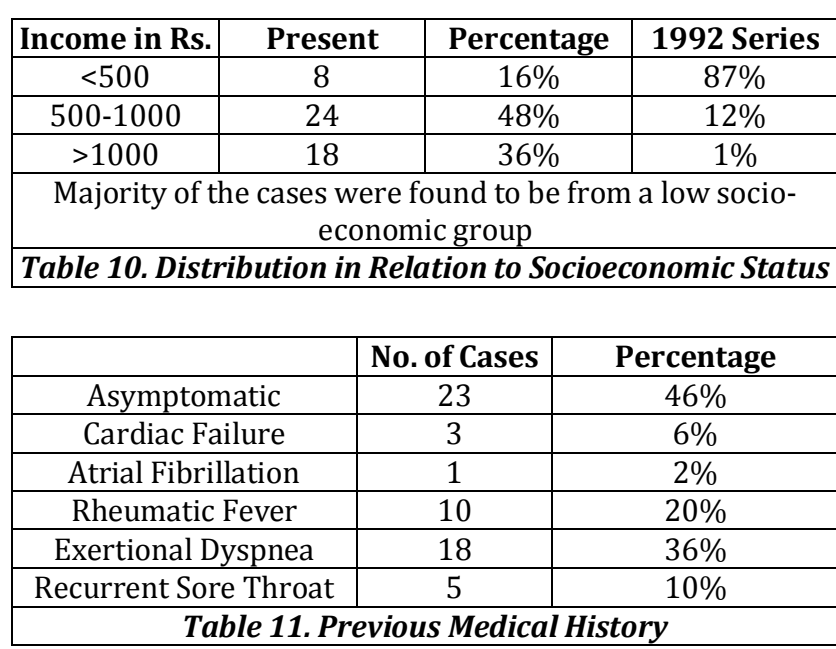

History of Rheumatic fever was noted in $20 \%$ of the cases, when compared to 1992 series it is $57 \%$ probably there is an improved medical service with an early diagnosis and treatment of streptococcal injections. It even shows that a subclinical streptococcal injection can cause the Rheumatic heart disease.

About $65 \%$ of primigravidas were found to be well compensated. About $63 \%$ of second gravidas were found to be well compensated. $50 \%$ of the VI gravidas were in functional class IV. It appears that higher the gravidity, poorer the prognosis. In this study with increasing parity, the age of the patients was also noted to be increasing.

There is a single death in the present study mortality rate in the 1992 GHH series was 5\%. This case was a third gravida aged about 37 years. Admitted as an unbooked case. For 24 weeks inevitable abortion with bleeding per vaginum. At the time of admission, the patient was a diagnosed case of CRHD severe MS with AE \& TR. anaemic and was in function- al class IV with sinus tachycardia. Few hours later she aborted and had AF and died soon after, in spite of the treatment given. In the past, this patient had undergone thyroid surgery 6 years back, but neither those medical records were available, nor she had any follow up at the endocrinology department. We could not definitely say whether she had thyrotoxicosis which precipitated AF or the CRHD with left atrial enlargement precipitated. 


\section{DISCUSSION}

Fifty cases of heart disease complicating pregnancy were studied to evaluate the influence of biological factors, when pregnancy is complicated by heart disease. And also, to study the changing trends in the disease process including the management aspect.

\section{Table 1. Incidence}

Incidence of cardiac disease was found to be $0.42 \%$ in the present study $92-95$. It was almost the same i.e. $0.43 \%$ in 1992 at Government Maternity Hospital.

\section{Table 2. Age Distribution}

Largest number of cases were found to be in the age groups 21-25 years like in 1992 series. But there is an increase percentage of cases in 16-20 age groups. In all the other age groups the \% incidence is less in present study.

The decreased Incidence in late age groups could be attributed to the effective family planning programme and also probably to completion of child bearing at an early age in women with heart disease.

\section{Table 3. Incidence in Relation to Gravidity}

In the present series there were $34 \%$ primis \& $66 \%$ multi gravidas. In 1977 study there were $27 \%$ primi \& 73\% multi gravidas

\section{Table 4}

There were 9 grand-multies in the present series this is to show that there is still a greater role on emphasizing the importance of family planning \& health education.

\section{Table 5. Residence Distribution}

Most of the cases in this study were from urban slum areas, majority were CRHD.

\section{Table 6 \& 7. Aetiology}

In the present study 70\% were CRHD, 18\% Congenital Heart Disease.

1 case of primary pulmonary hypertension; $3 \%$ cases of MVP 2 cases of conduction defects; 2 cases of cardiomyopathy \& one case of myocarditis.

Compared to 1992 series, the incidence of CRHD has decreased and the incidence of congenital heart disease has increased. Rheumatic heart disease this is on the decline but still exists in certain regions.

\section{Table 8 \& 9. Type of Lesion}

Mitral valve was involved in all the cases except in a case of Pure TR; pure MS contributed to a 42\%-compared-to- 1992 series it was $64.5 \%$

There is a slight increase in the incidence of MS \& MR (When occurred together) compared to 1992 study, probably because the mitral valvotomy cases developed Mitral insufficiency after CMV.

\section{Table 10. Socio Economic Status}

About $90 \%$ of the cases in this study were belonging to Low socio-economic class.

\section{Table 11. Previous History of Rheumatic Fever}

History of Rheumatic fever was noted in $20 \%$ of cases as compared to $57 \%$ in 1992 series. Probably this is due to an early diagnosis and treatment of streptococcal infections. This also shows that even sub clinical streptococcal infections could cause Rheumatic heart disease.

\section{Table 12. Relationship of Functional Grade to Age}

As age increases the functional grade seems to be increasing in this study. Of the three cases of functional Grade IV in 1620 age group: One primi subsequently had undergone closed mitral valvotomy \& after which she became functional Grade I. Other two cases were unbooked cases with multiple complications such as severe anaemia \& PIH, which are deleterious to a diseased heart.

\section{Table 13. Relation of Functional Class to Gravidity}

About $65 \%$ of the primigravidas were well compensated. About $63 \%$ of II Gravidas were well compensated

Gravidity from third downwards showed a percentage increase in the incidence of cases in Functional class IV.

In this study it is found that the higher the gravidity, poorer the prognosis, with high parity the age was also noted to be increasing.

\section{Table 14. Functional Class and Mortality}

There were no deaths in Class I, II, III the single death that has occurred in this study belonged to Class IV. The rest of the Class IV cases were managed well.

\section{Table 15. Associated Conditions}

Anaemia, $24 \%$ of cases had anemia with $\mathrm{Hb} \%$ less than 10 gms is this study as compared to $40 \%$ in 1992 series. In the 12 anaemic cases in the present study 4 had severe anemia with $\mathrm{Hb} \%$ less than 5 gms at admission. In this 4, two had nutritional anaemia. It is reasonable to confer that nutritional anaemia is still prevalent in a significant percentage of people. Anaemia has a deleterious effect on pregnant cardiac patients.

\section{Hypertensive Disorders of Pregnancy}

$22 \%$ of cases had pregnancy induced hypertension. PIH was noted to have a definite bearing on the functional class of the cases. Patients associated with severe PIH were in class IV.

\section{Respiratory Infections}

$26 \%$ of the cases suffered RTI some time or the other in the present pregnancies. They were given injection C.P. 10 lakhs 6th hourly and injection Gentamicin $60 \mathrm{mg}$ IM BD for 7-10 days.

In this study we had a case of a molar pregnancy. This patient has bleeding per vaginum and was severely anaemic. This was one of the cases who had undergone hysterectomy in this series, subsequent histopathology report revealed invasive mole.

Table 20. Cardiac Failure in Relation to the Period of Gestation

During the I Trimester there were 2 cases who subsequently had cardiac failure in II trimester also, they had CMV in the II trimester. The case who had a cardiac failure in II trimester expired. Maximum number of cardiac failures were noted during the intrapartum period and immediate post-partum 
period which is due to the maximum amount of haemodynamic changes that occurs during those periods.

\section{Table 16. Post Valvotomy Pregnancy}

There were 3 cases of Post valvotomy pregnancies in this study. Restenosis was not seen in these cases, though one of the cases had valvotomy 10 years back.

But Mitral insufficiency after valvotomy was a common finding all the three cases.

Two of the cases had CMV and one of the cases had a balloon valvuloplasty. International standards of restenosis following open procedures is $5 \%$ in 5 years and $60 \%$ in 9 years.

As per Wallace et al. 1971 the post-operative course was not influenced by child bearing. Atrial fibrillation is the most important factor influencing the course of disease after valvotomy. But in the present series we did not encounter any such complications.

\section{Table 18 \& 19. Valvotomy During Pregnancy}

\section{Indications for Surgery During Pregnancy}

1. Pure mitral stenosis which is progressive

2. Pure mitral stenosis which is refractory to medical treatment.

3. Class II \& IV patients with mitral stenosis who became pregnant.

The ideal time is between 18-24 weeks. Operative mortality is supposed to be high during pregnancy as compared to non-patients i, e. $5 \%$ in class III \& $20 \%$ in class IV (Gilchrist).

\section{Surgical Correction of Congenital Heart Disease}

It is ideal to have the congenital heart disease corrected prior to pregnancy but in the present study all the congenital heart disease cases were uncorrected.

\section{Table $21 \& 22$. Mode of Delivery}

$50 \%$ of the cases had SVD \& 14\% needed an assistance with outlet forceps. The caesarean section rate is high when compared to the previous studies reasons. The LSCS were done purely for obstetrical A case of severe primary pulmonary hypertension had undergone hysterotomy \& sterilization under epidural anaesthesia. In the present study 3 patients had MTP with less than 10 weeks' gestation, 2 had spontaneous abortions at 20- \& 24- weeks' gestation, 1 had hysterotomy sterilization.

\section{Table 23. Gestation Age at Birth}

1. One baby was born at 34 weeks.

2. 5 babies were border line premature.

3. 2 babies went up to 41 weeks.

1977 GMH series reported 24 preterm, 75 tern babies and one abortion. In the present series there is an increase in abortion rate probably because now are patients are more aware of MTP sterilization.

There is $50 \%$ decrease in the preterm deliveries compared to 1992 series.
Table 24

Presentation- commonest is VX presentation.

\section{Table 27. Birth Weights}

Birth weight over 2.5 kgs. iqs seen in about $58.5 \%$ of cases which is comparable to $1992 \mathrm{GMH}$ series which is $58 \%$.

In the present study there is a decrease in the percentage incidence in less than $2 \mathrm{~kg}$ weight group.

\section{Cause of Foetal Mortality}

There was one still birth, and it was in a case of rupture uterus. In the present study, the babies were not found to have congenital heart disease.

\section{Table 31. Maternal Mortality}

There was one maternal death in the present series. This case was a third gravida with 24 weeks GA with inevitable abortion and at admission was in class IV. She was anemic at admission. She had under gone thyroidectomy 6 years back and the medical records were not available. She developed atrial fibrillation and died few hours after she aborted.

\section{Lactation}

All the mothers breast fed their children. Only one case of feeding problem was encountered, and it was an IUGR baby. Class IV patients had an extended help from their families to look after the new born.

\section{CONCLUSION}

1. $1.50 \%$ patients with heart disease in pregnancy were reviewed for the period August 2017-2018. Incidence of heart disease is found to be $0.42 \%$.

2. Incidence of rheumatic heart disease has decreased, and the incidence of congenital heart diseases has increased.

3. The number of primi gravidas and second gravidas has increased. There were no 7th or 8th gravidas in the present study but there was an increase in the number of Grand multies

4. Maximum number of cases was seen in 21-25 years age group. But it is found that there is a percentage increase of the cases in 16-20 years age groups, which can be attributed to increased incidence of congenital heart disease in this study.

5. Age and gravidity were found to correlate with the functional class of heart disease.

6. Most of the study cases were from a low socio-economic group and from urban slums.

7. Most of them had vaginal deliveries and $20 \%$ had LSCS for obstetrical indications. The incidence of LSCS is noted to be rising.

8. Duration of labour both in primigravidas and multigravidas was found to be decreased when compared with the previous studies.

9. There is a decreased incidence in the preterm babies and babies weighing less than 2 Kgs, compared to 1992 study at GMH. No. of babies weighing more than $2.5 \mathrm{~kg}$ were comparable to the 1992 series.

10. Perinatal mortality was $23.25 / 1000$ births.

11. One maternal death in the fifty cases studied.

12. Among the post valvotomy pregnancies, one had a 34 weeks preterm delivery, one had a IUGR baby weighing 1.75 Kgs. IUGR could be due to PIH in this case. 
13. Cases who had valvotomy during this pregnancy fared well and had babies weighing $>2.9 \mathrm{~kg}$. They had no complications after the valvotomy during the course of pregnancy and delivery and puerperium.

14. Echocardiography is the diagnostic test of choice in the recent study. This was performed on all the cases.

15. Pregnancy outcome greatly varies when the pregnant cardiac is booked case and when she is constantly looked after by a cardiologist \& obstetrician with a touch of personal care. It is always advisable to have an expert neonatologist and an anaesthetist available at all the times.

16. Though most of the multigravidas are convinced to undergo sterilization, there remains a group of adamant grand multies who refused sterilization. This is the group which requires more personal attention so as to explain the risks of future pregnancies with advancing age and gravidity, especially on a diseased heart.

\section{REFERENCES}

[1] Twickler DM, Wendel GD Jr. Williams Obstetrics. 23 ${ }^{\text {rd }}$ edn. 2010: p. 959.

[2] Mishra R. Ian Donald's Practical obstetric problems. $7^{\text {th }}$ edn. Wolters and Kluwer India Pvt. Ltd., 2013: p. 185.

[3] Bourne AW. Recent advances in obstetrics and gynaecology. $2^{\text {nd }}$ edn. J \& A Churchill Publishers 1928.

[4] Misra R. Ian Donald's Practical obstetrics. 7th edn. 2013: p. 191.

[5] Devi SY. Laproscopic treatment of ectopic pregnancy. J Obstet \& Gynecol India 2000;50:69-74.

[6] Dewhurst J. Integrated obstetrics \& gynaecology for post graduate. $3^{\text {rd }}$ edn. Oxford: Blackwell 1981: p. 34850 .

[7] Arulkumaran S, Gopalan S, Kumar P, et al. Obstetrics and gynecology for postgraduates. $3^{\text {rd }}$ edn. 2009: p. 107.

[8] Jameson JL, Fauci AS, Kasper DL, et al. Harrison's Principles of Internal Medicine. 20th edn. McGraw-Hill Education Publisher 2018. 